of a general mathematical approach is being investigated.

A detailed paper is to be published shortly.

Royal Naval Scientific Service.

P. SAvic June 3.

1 Roper, C. G., and Engelberger, J. F., Electronics, 117 (Nov. 1947).

${ }^{2}$ Hill, A. V., J. Sci. Instr., 8, 262 (1931); 11, 281 (1934); Proc. Roy. Soc., B, 126, 680 (1944).

${ }^{3}$ Watton, W. L., J. Sci. Instr., 12, 115 (1935).

- Preston, J. S., J. Sci. Instr., 23, 173 (1946).

"Irwin, J. T., "Oscillographs" (Pitman, London, 1925).

'Butterworth, S., Wood, A. B., and Lakey, E. H., J. Sci. Instr., 4, 8 (1926).

' Bebb, A. H., J. Sci. Instr., 10, 362 (1933).

\section{Biological Properties of a Substance Isolated from Wheat Middlings and of Hydroxymethylfurfuraldehyde}

Following on the description many years ago ${ }^{1}$ of a growth-inhibiting constituent of yeast, a number of plant extractives ${ }^{2}$ and pure substances ${ }^{3}$ have been reported to possess similar activity. A distinctive feature in the case of most of them is that in cultures in vitro the growth of connective tissue cells is inhibited, but not that of epithelia. From this the conclusion was drawn that such action, if exerted in vivo, would lead to the retardation of growth in young animals since this depends upon the growth of their connective tissue, without interference with the vitality of such other tissues as the skin and blood-forming organs, the cells of which continue to multiply throughout normal life. A further inference was made that the growth of tumours might similarly be inhibited, since this too depends upon a parallel growth of stroma. These expectations were, in fact, to some extent realized ${ }^{4}$, but owing to the unsatisfactory nature of the material used the experiments were unconvineing.

It now appears that action of this kind is not specific, being shown in varying degree by a number of aldehydes ${ }^{5,6}$, lactones ${ }^{3,7}$ and other substances ${ }^{8}$ containing unsaturated groups.

In the course of further attempts to isolate the naturally occurring agent from plant sources a substance has been prepared from wheat middlings which is clearly of carbohydrate nature but has not yet been completely identified. In very brief outline the process is the following. Wheat middlings are quickly extracted with 80 per cent alcohol $\left(\frac{1}{2} \mathrm{hr}\right.$. stirring; all processes must be expeditiously conducted), the extract concentrated under diminished pressure below $60^{\circ}$ to a small volume, washed with benzene, concentrated below $60^{\circ}$ nearly to dryness, washed again with benzene, and excess absolute alcohol then added. The sticky solid precipitated is then twice extracted with hot absolute alcohol and the insoluble residue triturated with cold 95 per cent alcohol. The substance is then taken up in hot 95 per cent alcohol and the solution is evaporated under low pressure. A modification of this procedure has been employed in later experiments but the statements in the text apply to material made as described. Tested on young rats, it has been found to arrest growth at a daily dose of about $1 \mathrm{mgm}$., given by the mouth. The effect is immediate and ceases directly administration is discontinued.

During the progress of the work the probability seemed to emerge that a characteristic structural feature was a furanose group, for the product was convertible by acid to hydroxymethylfurfuraldehyde.
This substance had already been found effective in arresting the growth of rats, at a dose of about $2 \mathrm{mgm}$. per day, and similar activity was shown by the relatively insoluble polymer which tends to form spontaneously when hydroxymethylfurfuraldehyde, prepared in the pure state from cane sugar, is kept.

When tested on rats bearing the Walker carcinoma, all these three substances have been found to cause retrogression of the tumours, taking effect in about a week. The dose necessary for the purpose is considerably larger, namely, about $15-45 \mathrm{mgm}$. per rat per day in the case of hydroxymethylfurfuraldehyde; in all three cases it was noted that at this high level of dosage the increase of body-weight is no longer arrested but, if anything, accelerated.

In a future communication more details will be given and, it is hoped, an indication of the precise nature of the active substance which we have isolated from wheat middlings, or, in some experiments, from malt extract. The two are not necessarily identical though they appear to have similar properties.

We wish to express our obligation and thanks to Sir Robert Robinson for stimulating help and advice.

$$
\text { T. B. HEATON }
$$

Department of Pharmacology, and

$$
\text { G. M. RobrNson }
$$

Dyson Perrins Laboratory, University of Oxford. July 20.

${ }^{1}$ Heaton, J. Path. Bact., 29, 293 (1926),

2 Medawar, Robinson and Robinson, Nature, 151, 195 (1943).

${ }^{3}$ Haynes, Quart. Rev. Chem. Soc., 2, 46 (1948).

- Heaton, J. Path. Bact., 32, 565 (1929).

- Willmer and Wallersteiner, J. Physiol., 96, 16P (1939).

- Boyland, Biochem. J., 34, 1196 (1940).

${ }^{7}$ Haynes and Jones, J. Chem. Soc., 954 (1946).

${ }^{8}$ Andus and Quastel, Nature, 159, 320 (1947).

\section{Assay of norAdrenalin and Adrenalin in Extracts of Nerves and Tissues}

RECENT investigations have shown that the sympathomimetic activity present in several organs and in large amounts in adrenergic nerves, for example, the splenic nerves of cattle, is chiefly due to lævo-noradrenalin or $l$-arterenol, which has been identified by quantitative biological and colorimetric tests (Euler ${ }^{1,2}$ ). By using the cat's blood pressure in conjunction with the fowl's rectal cæcum (Barsoum and Gaddum ${ }^{3}$ ) as test preparations, showing activity ratios for $l$-adrenalin and $l$-noradrenalin of $1: 2-4$ and 20-30:1 respectively, adrenalin has been detected in extracts of spleen, and splenic nerves, in amounts corresponding to 1-4 per cent of that of noradrenalin.

The biological assays have been facilitated by using a method of purification, depending on adsorption of the sympathomimetic activity on aluminium hydroxide $\left(\mathrm{Shaw}^{4}\right)$. In order to increase the amount recovered with this method, the aluminium hydroxide, instead of being added as such, was formed in the trichloracetic acid extract of the organs by adding aluminium sulphate and sodium hydroxide. Adsorption was carried out at $p H$ 7, and was practically complete even with small amounts of aluminium hydroxide. The washed precipitate was dissolved in sulphuric acid, and the aluminium sulphate removed by precipitation with four volumes of ethanol at $p H \mathbf{H}$.5. About 70 per cent of the sympathomimetic activity was recovered by this procedure, and, since the extracts were only slightly coloured, and showed 